\title{
Impact of Pectin, Cellulose, and Lignin on Membrane Fouling Indicators during Cross-flow Microfiltration of Model Solutions \\ Gallego Ocampo HL ${ }^{1,2,4 *}$, Erickson LE², Velez Pasos CA ${ }^{1}$ and Barka FV ${ }^{3,4}$
}

${ }^{1}$ Escuela de Ingenieria de Alimentos, Universidad del Valle (UNIVALLE), Calle 13 \# 100-00, 760031, Santiago de Cali (Valle del Cauca), Colombia ${ }^{2}$ Chemical Engineering, Kansas State University (KSU), 1012 Durland Hall, Manhattan KS, USA

${ }^{3}$ Centre de Coopération Internationale en Recherche Agronomique pour le Développement (CIRAD), UMR 95 QUALISUD, 73 rue J.F. Breton, TA B-95/16, F-34398 Montpellier cedex 5, France

${ }^{4}$ Centro Nacional de Ciencia y Tecnología de Alimentos (CITA), Universidad de Costa Rica, San José, Costa Rica

\begin{abstract}
Microfiltration performance has been analysed by evaluating the influence of three macro-compounds as a function of the cross-flow velocity (CFV), transmembrane pressure (TMP) and pore size of the membranes. Four mathematical models were evaluated to relate the permeate flow rate $\left(\mathrm{J}_{\mathrm{p}}\right)$ to the concentration of the macrocompounds in the retentate $\left(\mathrm{C}_{\mathrm{b}}\right)$ during filtration in concentration mode. Pectin has a greater impact than cellulose and lignin on the permeate flux $\left(\mathrm{J}_{\mathrm{p}}\right)$. The largest value of $K_{2}$ was found for pectin in the model $J_{p}=K_{1}+K_{2} \cdot C_{b}^{-1}$. The optimum operating conditions and pore size to reduce fouling of the membranes depend on the pore size to particle size ratio and the physicochemical interactions between the solute and membrane. The mathematical model is useful in the region where the permeate flow is nearly independent of pressure, the pore size and cross-flow velocity but is dependent on the diffusional phenomenon of mass transfer.
\end{abstract}

Keywords: Membrane fouling; Cross-flow microfiltration; Model solution; Mathematical model; Fruit juice

\section{Nomenclature}

$a_{p}$ Equivalent spherical radius of macromolecule (m)

$A_{w}$ Water activity

$a, b$ Parameters in model for viscosity as a function of concentration, Equation 3

C Macro-compound concentration

$C_{0}$ Initial macro-compound concentration

$C_{b}$ Macro-compound concentration in the retentate

CFM Cross-flow microfiltration

CFV Cross-flow velocity

$D$ Diffusion coefficient

$d_{p}$ Spherical diameter $(\mathrm{nm})$

$J_{p} \quad$ Permeate flow rate $\left(\mathrm{m}^{3} \cdot \mathrm{m}^{-2} \cdot \mathrm{s}^{-1}\right)$

$K$ Boltzmann constant

$K_{1}$ Intercept of Equation $9\left(\mathrm{~m} \cdot \mathrm{s}^{-1}\right)$

$K_{2}$ Slope of Equation $9\left(\mathrm{~kg} \cdot \mathrm{m}^{-2} \cdot \mathrm{s}^{-1}\right)$

$L M$ Low methoxyl

$M W$ Molecular weight $\left(\mathrm{g} \cdot \mathrm{mol}^{-1}\right)$

PID Proportional integral derivative

PT Pressure transmitters

$P$-value Probability value

$P_{l o f}$ Probability value lack of fit

$R^{2}$ Correlation coefficient $t$ Time

$T$ Absolute temperature (K)

TMP Transmembrane pressure $(\mathrm{kPa})$

TSS Total soluble solids

$\mu$ Dynamic viscosity $\left(\mathrm{kg} \cdot \mathrm{m}^{-1} \cdot \mathrm{s}^{-1}\right)$

VCR Volumetric concentration ratio

$V_{d}$ Dead volume

$V_{p}$ Volume of permeate recovered

$V_{T}$ Total volume of solution treated

$\% w / v$ Weight/volume percent

\section{Introduction}

Cross-flow microfiltration (CFM) has been successfully applied to process an important variety of fruit juices, including those of tropical fruits, to minimize thermal damage of sensitive compounds $[1,2]$, to preserve nutritional and organoleptic properties, to provide microbiological stability $[3,4]$ and to develop new products, making subsequent purification processes easier. However, during microfiltration, the membranes tend to foul, which impacts the

*Corresponding author: Heidy Lorena Gallego Ocampo, Chemical Engineering, Kansas State University (KSU), 1012 Durland Hall, Manhattan KS. 66506, USA, Tel: +57 30056718 26; E-mail: heidy.gallego@correounivalle.edu.co

Received February 18, 2016; Accepted May 06, 2016; Published May 13, 2016

Citation: Ocampo HLG, Erickson LE, Pasos CAV, Barka FV (2016) Impact of Pectin, Cellulose, and Lignin on Membrane Fouling Indicators during Cross-flow Microfiltration of Model Solutions. J Membra Sci Technol 6: 150. doi:10.4172/21559589.1000150

Copyright: ( 2016 Ocampo HLG, et al. This is an open-access article distributed under the terms of the Creative Commons Attribution License, which permits unrestricted use, distribution, and reproduction in any medium, provided the original author and source are credited. 
economic and commercial viability of the process by reducing the specific permeate flow.

In the microfiltration of fruit juices, fouling is mainly attributed to the presence of suspended solids, including fragments of cell walls containing pectin, cellulose, smaller amounts of hemicellulose, hydroxyproline-rich proteins and lignin [5]. Potential phenomena include adsorption, precipitation, accumulation of these macrocompounds in the membrane porous structure, hydrodynamic forces, and the physicochemical interaction between these solutes and the membrane materials [6].

Aggregates, fibrous networks, lamellar structures or gels may foul the membranes, creating pore blockage and gel polarization, causing a decrease in the permeate flow through the membrane. Concentration polarization phenomena associated with the accumulation of macrocompounds at the surface of the membrane also reduces permeate flow. Some authors have attempted to improve permeation flux using pulsatile flow, counter-flows, turbulent flow, an external electric field and enzymatic hydrolysis [7-10]. Nonetheless, all juices behave differently, partially as a function of the concentration of fouling compounds; therefore, more research is needed to determine which macromolecules and interactions are most responsible for the fouling of the membranes. In this research the microfiltration performance has been analyzed by evaluating the influence of three macro-compounds -pectin, cellulose, and lignin- either alone or in mixture, as a function of the cross-flow velocity (CFV), transmembrane pressure (TMP) and pore size of the membranes in order to develop a mathematical model that relates the permeate flux to the concentration of macrocompounds in the model solutions.

\section{Materials and Methods}

The following materials were used for preparing model fluids: commercial citric pectin of high esterification of 70 to $75 \%$, type A of rapid fastening (Ceamsa, Pontevedra, Spain) and GENU ${ }^{\circ}$ pectin type 121 of slow fastening (CP Kelco product, file No. 0001064-01). These materials are high ester pectin products extracted from citrus peel and are standardized by the addition of sucrose. The texture was a freeflowing powder with less than $1 \%$ gum, a particle size less than 0.25 $\mathrm{mm}$ based on a $0.25 \mathrm{~mm}$ test sieve.. Insoluble cellulose, white fibrous powder, $97 \%$ pure, $\mathrm{pH}$ 5.0-7.5 (in solution at a concentration of $10 \%$ ), and water retention capacity of 1:5 (Tecnas product, PT-823) was used in addition to water-soluble lignin alkali with a low sulfonate content, with $4 \%$ sulphur impurities and a pH of 10.5 at $3 \mathrm{wt}$. \% lignin in water containing no reducing sugar (Sigma-Aldrich, PT-471003).

\section{Preparation of the model solutions}

Model solutions of pectin, cellulose and lignin were prepared based on the content found in tropical fruit juice.

Pectin solutions: Sucrose and pectin were mixed as a powder and added to $55-110$ - $\mathrm{L}$ of deionized water at $25^{\circ} \mathrm{C}$, depending on the pore size used, with constant agitation until the pectin was solubilized. Sucrose was added to obtain a solution containing 0.5 to $1.5 \% \mathrm{w} / \mathrm{v}$ of pectin and approximately $10 \% \mathrm{w} / \mathrm{v}$ sucrose to obtain a soluble solids content of $10 \pm 0.5^{\circ} \mathrm{Brix}$ as measured by a refractometer. The $\mathrm{pH}$ of the solution was adjusted to $4 \pm 0.11$ using food-grade sodium hydroxide.

Cellulose solutions: Cellulose $(0.04$ to $0.25 \% \mathrm{w} / \mathrm{v})$ and $10 \%$ sucrose were blended in the dry form and were added to a tank with deionized water at $25^{\circ} \mathrm{C}$. After gauging the volume (55-110-L) and adjusting the soluble solids ( $\left.{ }^{\circ} \mathrm{Brix}\right)$, the $\mathrm{pH}$ of the solution was standardized to 4 \pm 0.11 using food-grade citric acid. To prevent sedimentation of the cellulose, the solution was subjected to constant stirring.

Lignin solutions: Lignin ( 0.033 to $0.31 \% \mathrm{w} / \mathrm{v})$ was premixed with sucrose $(10 \%)$ and then solubilized in a tank with deionized water at $35^{\circ} \mathrm{C}$. After gauging the volume $(55-110-\mathrm{L})$ and adjusting the soluble solids, the $\mathrm{pH}$ of the solution was adjusted to $4 \pm 0.11$ using food-grade citric acid.

Mixture of components solutions: Different mixtures of these solutions were used, some with two solutions and others with three solutions. For binary mixtures (cellulose and pectin), pectin was first mixed in the dry form with sugar, and then cellulose was added before adding to a tank with deionized water. For ternary mixtures solutions, after solubilizing pectin and cellulose in deionized water, lignin was slowly added with constant stirring following the procedure for the adjustment of soluble solids and $\mathrm{pH}$, as mentioned above.

\section{Physical parameters evaluated}

The physical parameters were evaluated in the feed, permeate, and retentate streams to obtain the values of $\mathrm{pH}$, density, viscosity and soluble solids, according to classical procedures [11]. An Abbe refractometer (Atago model 1T, Japan, measurement accuracy of brix of $\pm 0.5 \%)$ was used to determine the soluble solids. The viscosity of the samples was determined at $35^{\circ} \mathrm{C}$ using a Cannon-Fenske viscometer and at $20^{\circ} \mathrm{C}$ with a Brookfield DV-III Ultra viscometer. A spindle S00 at $50 \mathrm{rpm}$ with a torque at $10 \mathrm{~N}-\mathrm{m}$, was used for the feed and retentate. The samples were analysed in triplicate. Then, the viscosity data were plotted versus concentration using non-linear regression with SigmaPlot program 10.

Main physico-chemical characteristics of the model fluids: The diffusivity of the macro-compounds through the bulk solution was estimated by modeling them as spherical particles. The Brownian diffusion coefficient for a spherical particle can be estimated by the Stokes-Einstein model as [12]

$$
D=\frac{K T}{3 \partial i d_{p}}
$$

where $K, T, \mu, d_{p}$ are the Boltzmann constant, absolute temperature, solution viscosity, and equivalent spherical diameter of the particle, respectively. The equivalent radius ( or the Stokes-Einstein radius, is in meters) for pectin and lignin was estimated using (Equation 2) $[13,14]$

$$
a_{p}=\left(0.262 \cdot(M W)^{0.5}-0.3\right) \cdot 10^{-10}
$$

The viscosity data of pectin and the pectin-cellulose-lignin mixture were plotted versus concentration $\left(\mathrm{C}_{\mathrm{b}}\right)$ using a non-linear regression SigmaPlot program 10, and an exponential relationship was found (Equation 3). The correlation coefficient $\left(\mathrm{R}^{2}\right)$ of the model for the pectin solution was 0.9665 , with $\mathrm{a}=8.00 \mathrm{E}-04$ and $\mathrm{b}=9.89 \mathrm{E}-02$, whereas for the pectin-cellulose-lignin mixture, $\mathrm{R}^{2}$ was 0.9061 , with $\mathrm{a}=5.70 \mathrm{E}-03$ and $\mathrm{b}=1.0835$.

$$
\mu=\frac{a \cdot\left(\exp \left(b \cdot C_{b}\right)-1\right)}{b}
$$

Therefore, using (Equation 3), we estimated the viscosity according to the macro-compound concentration in the retentate $\left(\mathrm{C}_{\mathrm{b}}\right)$. For the range of concentrations assessed in this work, and using the corresponding viscosity estimated using (Equation 3), a nearly linear relationship between the diffusion coefficient $\mathrm{D}$ and the inverse of the 


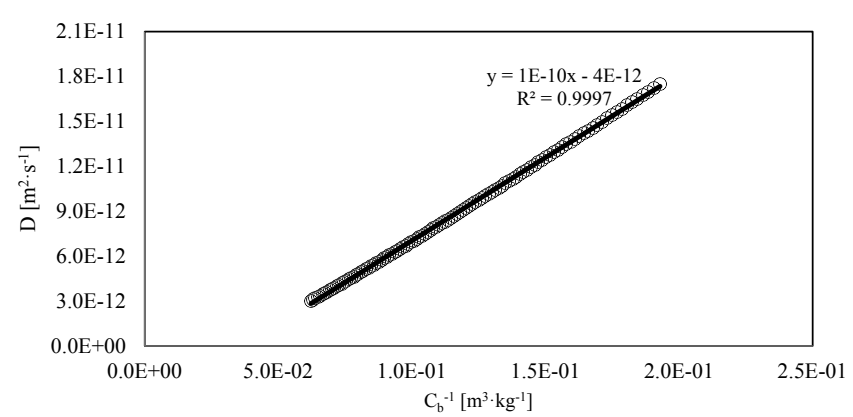

Figure 1: Relation between the inverse of the mass concentration and the diffusivity of the pectin solutions.

concentration was found (Figure 1).

Modeling of the permeation flow and definition of simple fouling indicators: During the cross-flow microfiltration, the concentration of compounds retained by the membrane can be estimated through the volumetric concentration ratio (VCR). A mass balance can be established on the basis of the following assumptions: a. there is total retention of macromolecules in the retentate and consequently no pectin, cellulose and lignin in the permeate, $b$. there is complete mixing of the macro-compounds, and c. the accumulation of solids at the membrane surface is negligible with respect to the total mass of particles in the retentate.

The balance is

$$
\frac{d\left(C \cdot V_{T}\right)}{d t}=0
$$

The total volume of solution treated was

$$
V_{T}=V_{p}+V_{d}
$$

where $V_{p}$ is the permeate volume and $V_{d}$ is the dead volume.

Integrating both sides of (Equation 4) with the boundary conditions

$$
\begin{aligned}
& t=0, \quad C=C_{0}, \quad V_{T}=V_{p}+V_{d} ; \quad t=t, \quad C=C_{\mathrm{b}}, \quad V_{T}=V_{d} \\
& C_{b}=C_{0} \cdot\left(\frac{V_{p}+V_{d}}{V_{d}}\right)=C_{0} \cdot V C R
\end{aligned}
$$

where $V C R$ is the volumetric concentration ratio. VCR can be measured over time by recording the volume of permeate recovered $\left(V_{p}\right)$ because in our close-loop system, the dead volume $\left(V_{d}\right)$ remains constant.

\section{Microfiltration}

The experimental procedure was performed using two different microfiltration systems: one without automation and the other partially automated but with the same characteristics in terms of the ceramic membrane's pore size and with the same range of operational variables.

The devices were provided with tubular ceramic membranes with $0.2 \mu \mathrm{m}, 0.5 \mu \mathrm{m}$, and $0.8 \mu \mathrm{m}$ pore size diameters (Membralox $1 \mathrm{P} 19$ 40, Pall-Exekia, Bazet, France). Each membrane had the following characteristics: 19 channels with a $4 \cdot 10^{-3} \mathrm{~m}$ internal diameter, $1.2 \mathrm{~m}$ length, and a total effective filtration area ranging from $0.22 \mathrm{~m}^{2}$ to $0.48 \mathrm{~m}^{2}$ depending on the equipment used. The first procedure was performed at the Universidad de Costa Rica (San José de Costa Rica)
[4]. The second procedure was partially automated and was conducted at the Universidad del Valle (Cali - Colombia) [15].

The filtration unit had a $50-\mathrm{L}$ feed tank. The start-up process was set according to the procedure suggested by Dornier [16]; the permeate valve was opened 30 minutes after adjusting the velocity and the pressure. The CFM of each model fluid was analysed by continuous feeding and constant collection of the permeate without removal of the retentate (concentration mode).

Permeation fluxes $\left(J_{\mathrm{p}}\right)$ were measured every minute using graduated containers of 2-L. All trials were conducted for approximately 2 hours. The membrane was washed after each trial until it reached at least $90 \%$ of the initial permeability $\left(20-\mathrm{L} \cdot \mathrm{h}^{-1} \cdot \mathrm{m}^{-2} \cdot \mathrm{kPa}^{-1}\right)$. The cleaning procedure suggested by Membralox [17] was slightly modified; in this case, $5 \mathrm{~g} \cdot \mathrm{L}^{-1}$ of hydrogen peroxide $\left(\mathrm{H}_{2} \mathrm{O}_{2}\right)$ was added to a sodium hydroxide $(\mathrm{NaOH}$, $2 \% \mathrm{w} / \mathrm{v}$ ) solution. After cleaning the membrane with this solution and rinsing it with water, a $5 \mathrm{~g} \cdot \mathrm{L}^{-1} \mathrm{H}_{2} \mathrm{O}_{2}$ in $0.5-1 \% \mathrm{v} / \mathrm{v} \mathrm{HNO}_{3}$ solution was used for a second cleaning, according to Gan et al. [18,19]. This cleaning formula can rapidly break down tenacious surface deposits and does not affect the ceramic membrane. The entire cleaning procedure was conducted at $90 \mathrm{kPa}$ and at cross-flow velocity of $5.0 \mathrm{~m} \cdot \mathrm{s}^{-1}$.

If the membrane had not reached at least $90 \%$ of its initial permeability, it was placed in an oven at $300^{\circ} \mathrm{C}$ until the organics were oxidized and was then cleaned with $0.5-1 \% \mathrm{v} / \mathrm{v}$ nitric acid $\left(\mathrm{HNO}_{3}\right)$ and $5 \mathrm{~g} \cdot \mathrm{L}^{-1} \mathrm{H}_{2} \mathrm{O}_{2}$ at $50^{\circ} \mathrm{C}$ for 20 minutes on each side of the membrane (permeate and retentate).

\section{Experimental design and data analysis}

The statistical analysis was made based on the response surface implemented Minitab 16 software in order to analyze the influence of three macro-compounds -pectin, cellulose, and lignin- either alone or in mixture, as a function of cross-flow velocity (CFV), transmembrane pressure (TMP) and ceramic membrane pore size and develop a mathematical model for predicting the fouling mechanism of the ceramic membranes and the permeate flow behavior. Additionally, an analysis of variance (ANOVA) and contour graphs were prepared to obtain the statistically significant effects of the variables, and interactions among them. The models to describe the decline of permeate flux with $\mathrm{C}_{\mathrm{b}}$ were validated according to the $\mathrm{P}$-value, $\mathrm{P}_{\text {lof }}$ and graph of the residuals.

In a Doehlert network for alone compounds [20-23], which describes a spherical experimental domain and stresses uniformity in space filling, the number of levels is not the same for all variables. This property allows a free choice of the factors to be assigned to a large or a small number of levels. As a general rule, it is preferable to choose the variable with the stronger effect, in this case, the CFV has 6 levels (3 $\mathrm{m} \cdot \mathrm{s}^{-1}, 3.67 \mathrm{~m} \cdot \mathrm{s}^{-1}, 4 \mathrm{~m} \cdot \mathrm{s}^{-1}, 4.33 \mathrm{~m} \cdot \mathrm{s}^{-1}, 4.67 \mathrm{~m} \cdot \mathrm{s}^{-1}$, and $\left.5 \mathrm{~m} \cdot \mathrm{s}^{-1}\right)$, the TMP has 5 levels $(90 \mathrm{kPa}, 168 \mathrm{kPa}, 245 \mathrm{kPa}, 323 \mathrm{kPa}$, and $400 \mathrm{kPa})$, and pore size only has 3 levels $(0.2 \mu \mathrm{m}, 0.5 \mu \mathrm{m}$, and $0.8 \mu \mathrm{m})$. Duplicates were performed on the axial and central points.

The Box-Behnken design was used for different mixtures of the macro-compounds [24], in this case, the $2^{\mathrm{k}}$ factorial design was combined with incomplete blocks to reduce the number of experiments to 15 with three replicates in the center. Each factor had 3 levels: TMP $(180 \mathrm{kPa}, 255 \mathrm{kPa}$, and $330 \mathrm{kPa})$, pectin concentration $(0.25 \%, 0.5 \%$, and $0.75 \%)$ and cellulose concentration $(0.04 \%, 0.06 \%$, and $0.08 \%)$ which allowed to determine the effect of the factors on each response. 
Citation: Ocampo HLG, Erickson LE, Pasos CAV, Barka FV (2016) Impact of Pectin, Cellulose, and Lignin on Membrane Fouling Indicators during Cross-flow Microfiltration of Model Solutions. J Membra Sci Technol 6: 150. doi:10.4172/2155-9589.1000150

Page 4 of 9

Pectin-cellulose-lignin mixtures, were used with a mixture simplex lattice design $[2,3]$. The pectin concentration was between $0.44 \%$ and $0.717 \%$, cellulose was between $0.04 \%$ and $0.25 \%$ and lignin was between $0.033 \%$ and $0.31 \%$.

\section{Results and Discussion}

\section{Main physico-chemical characteristics of the model fluids}

In Table 1 , the main physico-chemical properties of each of the flow streams are shown during microfiltration of the pure model solution of pectin, cellulose, lignin, and some combination of macrocompounds. All solutions were prepared with sucrose at the same total soluble solids level (TSS) $(10.5 \pm 0.5)$ with an initial concentration of macro-compounds corresponding to the average content found in fruit juices.

The density of the solutions remained almost constant during the CFM experiments. For all solutions, the viscosities varied greatly in the feed, permeate and retentate. The permeate viscosity remained lower and constant during the entire microfiltration time, whereas viscosity increased steadily in the retentate, according to the volumetric concentration ratio (VCR).

Because the cellulose settled rapidly, it was not possible to assess the suspension viscosity. The Reynolds numbers of the feed and

\begin{tabular}{|c|c|c|c|c|c|c|c|}
\hline Compound & Pore size $(\mu \mathrm{m})$ & $\operatorname{CFV}\left(m \cdot s^{-1}\right)$ & STREAM & TSS ( ${ }^{\circ}$ Brix) & $\rho 20^{\circ} \mathrm{C}\left[\mathrm{kg} \cdot \mathrm{m}^{-3}\right]$ & $\mu 20^{\circ} \mathrm{C}[\mathrm{Pa} \cdot \mathrm{s}]$ & $\operatorname{Re}$ \\
\hline \multirow{8}{*}{ Pectin $10 \mathrm{~kg} \cdot \mathrm{m}^{-3}$} & \multirow{8}{*}{$0.2,0.5,0.8$} & \multirow{8}{*}{ 03-May } & \multirow{2}{*}{ Feed } & 10.53 & 1046.3 & 0.1692 & \multirow{4}{*}{$74.21-123.68$} \\
\hline & & & & $(0.049) a$ & (1.66)a & $(0.008) a$ & \\
\hline & & & \multirow{2}{*}{ Permeate } & 8.9 & & 0.0028 & \\
\hline & & & & $(0.57) \mathrm{a}$ & & (0.0015)a & \\
\hline & & & Retentate $20-80 \mathrm{~min}$ & 10.98 & & 0.2109 & \multirow{4}{*}{$23.25-99.22$} \\
\hline & & & \multirow{3}{*}{ VCR: $1.19-3.45$} & $(0.46) a$ & & $(0.035) a$ & \\
\hline & & & & 11.55 & & 0.54 & \\
\hline & & & & $(0.45) a$ & & $(0.073) a$ & \\
\hline \multirow{8}{*}{ Cellulose $1.2-4.8 \mathrm{~kg} \cdot \mathrm{m}^{-3}$} & \multirow{8}{*}{$0.2,0.5,0.8$} & \multirow{8}{*}{ 03-May } & \multirow{2}{*}{ Feed } & 10.41 & 1081.09 & & \\
\hline & & & & $(0.14) a$ & $(58.82) \mathrm{a}$ & & \\
\hline & & & \multirow{2}{*}{ Permeate } & 10.09 & & & \\
\hline & & & & (0.099)a & & & \\
\hline & & & \multirow{2}{*}{ Retentate $20-80 \mathrm{~min}$} & 10.34 & & & \\
\hline & & & & $(0.057) \mathrm{a}$ & & & \\
\hline & & & \multirow{2}{*}{ VCR: $1.20-7.72$} & 10.9 & & & \\
\hline & & & & (0.071)a & & & \\
\hline \multirow{8}{*}{ Lignin $0.52-3.6 \mathrm{~kg} \cdot \mathrm{m}^{-3}$} & \multirow{8}{*}{$0.2,0.5,0.8$} & \multirow{8}{*}{5} & \multirow{2}{*}{ Feed } & 10.3 & 1045.34 & 0.00167 & $7511.42-12519.04$ \\
\hline & & & & $(0.23) a$ & $(3.20) a$ & (3.60E-05)a & \\
\hline & & & \multirow{2}{*}{ Permeate } & 10.04 & & & \\
\hline & & & & $(0.17) a$ & & & \\
\hline & & & \multirow{2}{*}{ Retentate $20-80 \mathrm{~min}$} & 10.47 & & & \\
\hline & & & & $(0.15) a$ & & & \\
\hline & & & \multirow{2}{*}{ VCR: $1.19-25.90$} & 10.87 & & & \\
\hline & & & & $(0.12) a$ & & & \\
\hline \multirow{6}{*}{ Pectin, Cellulose } & & & & 10 & 1093 & & \\
\hline & & & reed & $(0.15) \mathrm{a}$ & $(0.0014) a$ & & \\
\hline & & & Permeate & 9.75 & & & \\
\hline & & & Permeate & $(0.36) a$ & & & \\
\hline & & & Retentate & 11.2 & & & \\
\hline & & & VCR: $1.30-10.42$ & $(0.59) a$ & & & \\
\hline & & & & 10.1 & 1032.44 & 0.0513 & \\
\hline & & & reed & $(0.14) a$ & $(2.8374) \mathrm{a}$ & $(0.0021) a$ & \\
\hline & & & & 9.23 & & & \\
\hline Pectin Cellulnce lianin & 08 & & Permeate & $(0.14) a$ & & & \\
\hline Pectin, Celiurose, mgnin & 0.8 & 5 & & 10.43 & & & 402.51 \\
\hline & & & Retentate $80-100 \mathrm{mIn}$ & $(0.34) a$ & & & \\
\hline & & & VCR. $120-436$ & 10.6 & & & \\
\hline & & & $V C R .1 .20-4.36$ & $(0.32) a$ & & & \\
\hline & & & & 13.13 & 1056.32 & & \\
\hline & & & reed & $(0.32) a$ & 1056.32 & 0.0128 & 1650.5 \\
\hline Uchuva iuice & 08 & & Permeate & 12.82 & & & \\
\hline ucriuva juice & 0.8 & 5 & remeate & $(0.31) a$ & & 0.0635 & 332.1 \\
\hline & & & Retentate & 13.42 & & 0.0695 & 303.98 \\
\hline & & & VCR: $1.38-6.06$ & $(0.98) a$ & & 0.0090 & 303.98 \\
\hline
\end{tabular}

a Between brackets, the standard deviation.

Table 1: Main physical properties of each of the flow streams. 
retentate streams were always in the range of laminar flow except for lignin (Table 1), which is consistent with the results of Capannelli et al. [25] for the flow of juices with ceramic membranes. According to the inversely proportional relationship between Reynolds number and the concentration polarization found by Rezaei et al. [26], it can affirm that the small increase in the Reynolds number observed between the different model fluids allows decrease the fouling velocity.

A change in TSS between the permeate and retentate streams can also be observed in Table 1 . In pectin solutions, the TSS retention was between 6.25 and $12.78 \%$, whereas it increased in the solutions of cellulose and lignin to $1.62-3.96 \%$ and $5.47-5.57 \%$, respectively. The significant change in TSS values observed in the pectin solution is due to the ability of pectin to form a gel in the limit layer at lower water activity $\left(\mathrm{A}_{\mathrm{w}}\right)$ in the presence of sucrose, requiring more amount of sucrose. The smallest change in TSS observed for the cellulose solution may be due to the ability of cellulose to absorb water without interacting with sucrose (which passes through the membrane pores).

According to Sulaiman et al. [27], pectin has an average molecular weight of 70,000 $\mathrm{Da}\left(\mathrm{g} \cdot \mathrm{mol}^{-1}\right)$, whereas lignin has an average molecular weight of $10,000\left(\mathrm{~g} \cdot \mathrm{mol}^{-1}\right)$ [28]. Based on Equation 2, the equivalent spherical diameters of pectin and lignin were $6.90 \mathrm{~nm}$ and $2.59 \mathrm{~nm}$, respectively; therefore, pectin-cellulose and pectin-cellulose-lignin mixtures may be characterized by the size distribution of polydisperse particles because the cellulose particles have the greatest size of the three macro-compounds. Lu et al. [29], Zhao et al. [30] found that the equivalent spherical cellulose nanocrystals size varies between 15 to 40 nm.

\section{Modeling of the permeation flow and definition of simple fouling indicators}

Figure 2 shows an example of the experimental permeate flux $J_{p}$ for an aqueous pectin solution as a function of the inverse of the macrocompounds concentration $\left(C_{b}^{-1}\right)$ retained at different transmembrane pressures. For all trials, $J p$ was recorded between 5 and 10 min after starting, when the pressure-independent region was reached, and after the particle gradient near the membrane was established. The value of $\left(C_{b}^{-1}\right)$ was found using Equation 6.

Taking into account the relationship between viscosity data versus concentration, and on the understanding of the diffusivity variation with viscosity, macro-compound concentration, gel layer formation and mass transfer process during filtration, four empirical models were proposed and tested to relate the permeate flux to the macrocompound concentration $\left(\mathrm{C}_{\mathrm{b}}\right)$.

To model the permeate flux behavior as a function of concentration, was performed linear regressions to find an empirical model for a better representation of the variations between the permeate flow and the macro-compound concentration in the retentate flow. These four models are:

$$
\begin{aligned}
& J_{p}=K_{1}+K_{2} \cdot C_{b} \\
& J_{p}=K_{1}+K_{2} \cdot \ln \left(C_{b}\right) \\
& J_{p}=K_{1}+K_{2} \cdot\left(\frac{1}{C_{b}}\right) \\
& \frac{1}{J_{p}{ }^{2}}=K_{1}+K_{2} \cdot C_{b}^{b}
\end{aligned}
$$

The results from the experimental data analysis obtained with each model are shown in Table 2. According to the $\mathrm{R}^{2}$, P-value, $\mathrm{P}_{\text {lof }}$ and graph of the residuals (not shown) obtained from replicates in the axial and central points, the empirical model that best described the permeate flux behavior $J_{p}$ in the pressure-independent region for both pectin and cellulose was Equation 9. The repeatability study was satisfactory for each fluid model analysed, where the parameters $K_{1}$ and $\mathrm{K}_{2}$ were reproducible between trials at different initial concentrations of macro-compounds under the same process conditions. The results for several experiments with pectin are shown in Table 3.

The membrane fouling process could be due to several factors, such as cake formation, adsorptive fouling and pore blocking mechanisms that control the permeate flow through ceramic tubular membrane and change the membrane characteristics and lead to an increase of filtration resistance [31]. The presence of its effects is confirmed by the parameters $\mathrm{K}_{1}$ and $\mathrm{K}_{2}$ which determine the velocity of the solvent through the fouling layer and the membrane.

According to Equation 9, the parameter $\mathrm{K}_{1}$ (intercept) has velocity dimensions $\left(\mathrm{m} \cdot \mathrm{s}^{-1}\right)$ and may be related to the mass transfer coefficient. In this sense, $\mathrm{K}_{1}$ determines the velocity of the solvent through the fouling layer and the membrane when $\mathrm{C}_{\mathrm{b}}$ is infinite. Parameter $\mathrm{K}_{2}$ (slope) has mass dimensions per square meters of membrane over time $\left(\mathrm{kg} \cdot \mathrm{m}^{-2} \cdot \mathrm{s}^{-1}\right)$, the value of $\mathrm{K}_{2}$ depends on how the permeate flux, $J_{p}$, varies with the inverse of macro-compound concentration, $\left(C_{b}^{-1}\right)$. Figure 1 shows that the diffusivity of the macro-compound, $D$, is also proportional to $\left(C_{b}^{-1}\right)$. Thus, the second term in Equation 9 is related to the effect diffusivity on permeate flux. The concentration of macrocompounds at the membrane surface affects the rate of surface renewal and the removal of macro-compounds from the membrane surface by the flow of retentate past the membrane.

The concept of surface renewal of the fouling layer was introduced previously [32-38] and was used to describe the process of cross-flow ultrafiltration and microfiltration. The process model in this paper differs because in the previous model, the increase in concentration of the material retained was not considered [36].

The values of $\mathrm{K}_{1}$ and $\mathrm{K}_{2}$ determine the velocity of the permeate flux; for example, in the case where both parameters have high values, high

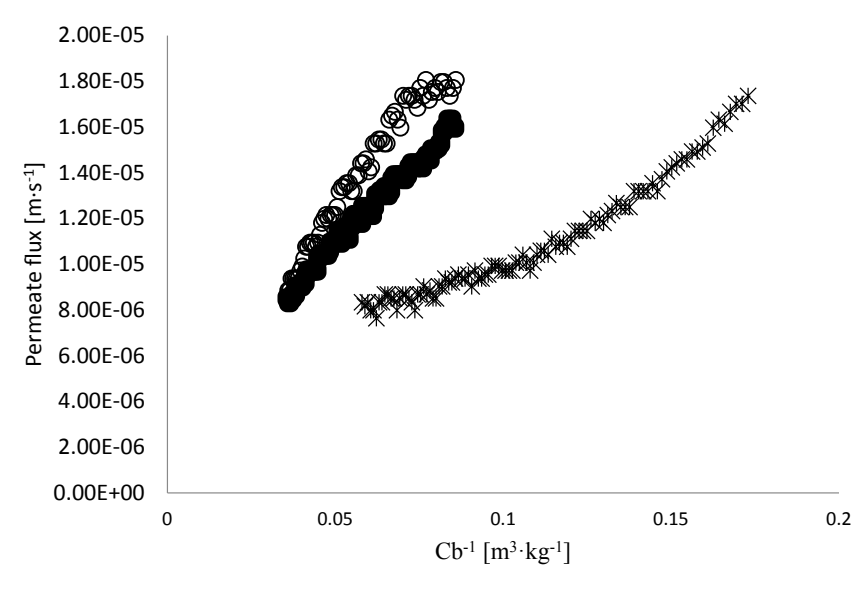

$* 323 \mathrm{kPa}, 3.67 \mathrm{~m} \cdot \mathrm{s}^{\wedge}-1.0 .2 \mu \mathrm{m}$

$0323 \mathrm{kPa}, 5 \mathrm{~m} \cdot \mathrm{s}^{\wedge}-1.0 .5 \mu \mathrm{m}$

- $323 \mathrm{kPa}, 4.33 \mathrm{~m} \cdot \mathrm{s}^{\wedge}-1.0 .8 \mu \mathrm{m}$

Figure 2: Cross flow microfiltration of diluted solutions of pectin at different compositions, pressures, velocities and sizes of pore. Procedure 2, pectin type 121. 
Citation: Ocampo HLG, Erickson LE, Pasos CAV, Barka FV (2016) Impact of Pectin, Cellulose, and Lignin on Membrane Fouling Indicators during Cross-flow Microfiltration of Model Solutions. J Membra Sci Technol 6: 150. doi:10.4172/2155-9589.1000150

Page 6 of 9

\begin{tabular}{|c|c|c|c|c|c|c|c|c|c|c|}
\hline \multirow{2}{*}{ MODEL } & \multicolumn{5}{|c|}{$\begin{array}{c}\text { PECTIN }{ }^{\mathrm{a}} \\
\left(5-10 \mathrm{~kg} \cdot \mathrm{m}^{-3}\right)\end{array}$} & \multicolumn{5}{|c|}{$\begin{array}{l}\text { CELLULOSE } \\
\left(1.2-4.8 \mathrm{~kg} \cdot \mathrm{m}^{-3}\right)\end{array}$} \\
\hline & $\begin{array}{l}\mathrm{K}_{1}^{*} \mathbf{1 0}^{-5} \\
\left(\mathrm{~m} \cdot \mathrm{s}^{-1}\right)\end{array}$ & $\begin{array}{c}\mathrm{K}_{2}^{*} 10^{-5} \\
\left(\mathrm{~kg} \cdot \mathrm{m}^{-2} \cdot \mathbf{s}^{-1}\right)\end{array}$ & $\mathbf{R}^{2}(\%)$ & $\begin{array}{c}P \text { - } \\
\text { value }\end{array}$ & $\begin{array}{l}\text { P-Lack } \\
\text { of fit }\end{array}$ & $\begin{array}{l}\mathrm{K} 1^{*} 10^{-5} \\
\left(\mathrm{~m} \cdot \mathrm{s}^{-1}\right)\end{array}$ & $\begin{array}{c}\mathrm{K}_{2}^{*} \mathbf{1 0}^{-5} \\
\left(\mathbf{k g} \cdot \mathrm{m}^{-2} \cdot \mathbf{s}^{-1}\right)\end{array}$ & $\begin{array}{l}R^{2} \\
(\%)\end{array}$ & P-value & $\begin{array}{c}\text { P-Lack } \\
\text { of fit }\end{array}$ \\
\hline$J_{p}=K_{1}+K_{2} \cdot C_{b}$ & 1.885 & -0.076 & 0.79 & $>0.01$ & 0.498 & 3.874 & -0.180 & 0.63 & $>0.01$ & 0.783 \\
\hline$J_{p}=K_{1}+K_{2} \cdot \ln \left(C_{b}\right)$ & 2.917 & -0.798 & 0.89 & $>0.01$ & 0.720 & 3.984 & -0.647 & 0.74 & $>0.01$ & 0.857 \\
\hline$J_{p}=K_{1}+K_{2} \cdot\left(\frac{1}{C_{b}}\right)$ & 0.297 & 7.453 & 0.95 & $>0.01$ & 0.927 & 2.578 & 1.899 & 0.79 & $>0.01$ & 0.901 \\
\hline$\frac{1}{J_{p}^{2}}=K_{1}+K_{2} \cdot C_{b}$ & $-0.22 E+04$ & $1.13 \mathrm{E}+04$ & 0.93 & $>0.01$ & 0.946 & $6.2 \mathrm{E}+03$ & $1.01 \mathrm{E}+03$ & 0.73 & $>0.01$ & 0.847 \\
\hline
\end{tabular}

a Values obtained from pectin at $323 \mathrm{kPa}$ and $3.67 \mathrm{~m} \cdot \mathrm{s}^{-1}$ with ceramic membranes of $0.2 \mu \mathrm{m} .{ }^{\mathrm{b}}$ Values obtained from cellulose at $245 \mathrm{kPa}$ and $4.67 \mathrm{~m} \cdot \mathrm{s}^{-1}$ with ceramic membranes of $0.2 \mu \mathrm{m}$

Table 2: Estimated parameter values are shown for pectin and cellulose for the models, Equations 7 , 8 , 9and 10 . These are the average values from experiments at different initial concentrations of macromolecules, pore size membranes, transmembrane pressures and cross-flow velocities.

\begin{tabular}{|c|c|c|c|c|c|}
\hline$P_{\mathrm{tm}}(\mathrm{kPa})$ & $\operatorname{CFV}\left(m \cdot s^{-1}\right)$ & Pore size $(\mu \mathrm{m})$ & $K_{1}\left(m \cdot s^{-1}\right)$ & $K_{2}\left(\mathrm{~kg} \cdot \mathrm{m}^{-2} \cdot \mathrm{s}^{-1}\right)$ & $\mathbf{R}^{2}$ \\
\hline \multirow{2}{*}{168} & \multirow{2}{*}{3.67} & \multirow{2}{*}{0.2} & 6.08E-06 & 6.57E-05 & \multirow{2}{*}{0.9261} \\
\hline & & & $-1.51 \mathrm{E}-07$ & $-2.17 \mathrm{E}-06$ & \\
\hline \multirow{2}{*}{323} & \multirow{2}{*}{3.67} & \multirow{2}{*}{0.2} & 3.63E-06 & 7.02E-05 & \multirow{2}{*}{0.9459} \\
\hline & & & $-2.64 \mathrm{E}-07$ & $-2.08 \mathrm{E}-06$ & \\
\hline \multirow{2}{*}{245} & \multirow{2}{*}{4.67} & \multirow{2}{*}{0.2} & $9.00 \mathrm{E}-08$ & $6.38 \mathrm{E}-05$ & \multirow{2}{*}{0.9217} \\
\hline & & & $-2.56 \mathrm{E}-07$ & $-1.92 \mathrm{E}-06$ & \\
\hline \multirow{2}{*}{245} & \multirow{2}{*}{4} & \multirow{2}{*}{0.5} & 6.69E-06 & $1.00 \mathrm{E}-04$ & \multirow{2}{*}{0.9661} \\
\hline & & & $-2.12 \mathrm{E}-07$ & $-3.12 \mathrm{E}-07$ & \\
\hline \multirow{2}{*}{400} & \multirow{2}{*}{4} & \multirow{2}{*}{0.5} & 4.41E-06 & $2.00 \mathrm{E}-04$ & \multirow{2}{*}{0.9583} \\
\hline & & & $-2.40 \mathrm{E}-07$ & $-4.01 \mathrm{E}-06$ & \\
\hline \multirow{2}{*}{323} & \multirow{2}{*}{5} & \multirow{2}{*}{0.5} & $2.61 \mathrm{E}-06$ & $2.00 \mathrm{E}-04$ & \multirow{2}{*}{0.9602} \\
\hline & & & $-2.89 \mathrm{E}-07$ & $-4.79 \mathrm{E}-06$ & \\
\hline \multirow{2}{*}{90} & \multirow{2}{*}{4} & \multirow{2}{*}{0.5} & 4.16E-06 & 1.00E-04 & \multirow{2}{*}{0.9655} \\
\hline & & & $-1.64 \mathrm{E}-07$ & $-2.45 E-06$ & \\
\hline \multirow{2}{*}{168} & \multirow{2}{*}{3} & \multirow{2}{*}{0.5} & $5.40 \mathrm{E}-06$ & $9.89 \mathrm{E}-05$ & \multirow{2}{*}{0.9773} \\
\hline & & & $-1.21 \mathrm{E}-07$ & $-1.86 \mathrm{E}-06$ & \\
\hline \multirow{2}{*}{323} & 3 & 05 & 7.18E-06 & 8.77E-05 & 09483 \\
\hline & 3 & 0.0 & $-1.61 \mathrm{E}-07$ & $-2.48 \mathrm{E}-06$ & 0.9483 \\
\hline 168 & 5 & 05 & $2.11 \mathrm{E}-06$ & $2.00 \mathrm{E}-04$ & 09535 \\
\hline 100 & 5 & 0.5 & $-2.80 \mathrm{E}-06$ & $-3.89 E-06$ & 0.9000 \\
\hline 323 & 33 & 08 & $3.22 \mathrm{E}-06$ & $2.00 \mathrm{E}-04$ & 0877 \\
\hline $0<0$ & 4.00 & 0.0 & $-1.15 \mathrm{E}-07$ & $-1.92 \mathrm{E}-06$ & 0.5011 \\
\hline 168 & 4.33 & 08 & 2.67E-06 & $1.00 \mathrm{E}-04$ & 09775 \\
\hline & & & $-1.59 \mathrm{E}-07$ & $-2.58 \mathrm{E}-06$ & 0.9175 \\
\hline 215 & 323 & 08 & 3.74E-06 & 1.00E-04 & \\
\hline 245 & 3.33 & 0.8 & $-1.52 \mathrm{E}-07$ & $-2.36 \mathrm{E}-06$ & $0.9 / 28$ \\
\hline
\end{tabular}

in brackets: standard error

Table 3: Estimated parameter values are shown for pectin at different initial concentrations, pore sizes, transmembrane pressures and cross-flow velocities for Equation 9.

$J_{p}=K_{1}+K_{2} \cdot\left(\frac{1}{C_{b}}\right)$

permeate flows are obtained because the flow through the fouling layer and the membrane is high, as is the removal of macro-compounds. Therefore, the velocity with which macro-solutes diffuse is also greater.

In the case where $\mathrm{K}_{1}$ is zero, the velocity of the solvent through the fouling layer and the membrane decreases drastically, representing a possible compaction of the fouling layer by the action of TMP, whereby the velocity of the removal of solutes and the permeate flux are minimal. In this case, $K_{2}=J_{p} \cdot C_{b}$ would be indicative of the velocity with which the macro-solutes are deposited on the compact layer $m_{c}(t)=K_{2}=\int_{0}^{t} J_{p} \cdot C_{b} d t \quad$ [38]. When $\mathrm{K}_{2}$ is zero, the flow is limited by the resistance of the membrane and the concentration of macromolecules has no effect [39].

The values of $\mathrm{K}_{1}$ and $\mathrm{K}_{2}$ obtained for individual macro-compounds showed that pectin had the lowest value of $K_{1}$ and the highest value of 
Citation: Ocampo HLG, Erickson LE, Pasos CAV, Barka FV (2016) Impact of Pectin, Cellulose, and Lignin on Membrane Fouling Indicators during Cross-flow Microfiltration of Model Solutions. J Membra Sci Technol 6: 150. doi:10.4172/2155-9589.1000150

$\mathrm{K}_{2}$; in this case, the tendency to form gel prevents the macro-solutes of pectin deposited from being easily removed from the membrane surface, which adds a considerable resistance to the flow. On the other hand, cellulose had intermediate values of $\mathrm{K}_{1}$ and $\mathrm{K}_{2}$ (Table 2).

The molecular weight of the cellulose and the shear stress exerted by the cross-flow velocity caused a dynamic balance between convective flow and diffusive flow and reducing the formation of the polarized layer, which increases the mass transfer and the permeate flows and decreases the subsequent membrane cleaning process [40]. The highest values of $K_{1}$ reported by lignin may be due to the ease of foaming in the presence of water and the turbulent flow developed in the retentate stream by action of the CFV (Table 1). The solubility of lignin in water can cause it to agglutinate near the membrane surface, thereby decreasing the velocity with which macro-solutes are removed from the surface (low values of $\mathrm{K}_{2}$ ), nevertheless, the turbulent flow easily removes the macro-solutes accumulated on the membrane surface [41-43]. Banerjee and De [44] found that the turbulent flow near the membranes drags the particles that accumulate on the gel layer so that the thickness of the gel layer decreases with increasing Reynolds number. Furthermore Verma and Sarkar [45] found that turbulent flow increases the mass transfer coefficient.

Influence of the hydrodynamic conditions and membrane pore size on $K_{1}$ and $K_{2}$ parameters: Depending on the macro-compound used, the CFV, TMP and pore size can positively or negatively influence the values of $K_{1}$ and $K_{2}$. For example, when the CFM is performed with the pectin fluid model at a pore size of $0.5 \mu \mathrm{m}$, a higher value of $\mathrm{K}_{1}$ is obtained $\left(4.8 \times 10^{-6} \mathrm{~m} \cdot \mathrm{s}^{-1}\right)$, whereas increasing CFV decreases $\mathrm{K}_{1}$ (Figures 3-6). It is known that membranes with higher pore size tend to be more susceptible to particles deposition and to fouling and, consequently, display higher permeate flux decline [46].

Additionally, an increase of CFV, TMP and pore size produces higher values of $\mathrm{K}_{2}$. The negative effect of CFV on $\mathrm{K}_{1}$ and the positive effect of TMP on $\mathrm{K}_{2}$ indicates that mass transfer is limited by TMP during the CFM of the pectin fluid model, given the tendency to form gel and deposited on the membrane surface increasing the thickness of gel layer and the permeate flow resistance, while the intermediate pore blocking and complete pore blocking contributed to the overall fouling mechanism $[47,48]$.

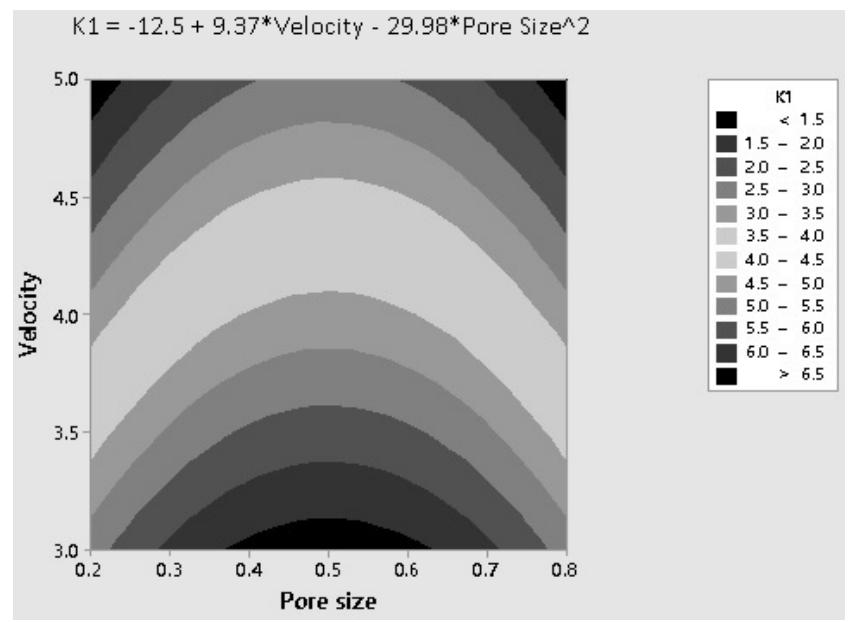

Figure 3: Contour graph $\mathrm{K}$, for pectin. Interactions among significant variables (velocity, pore size).

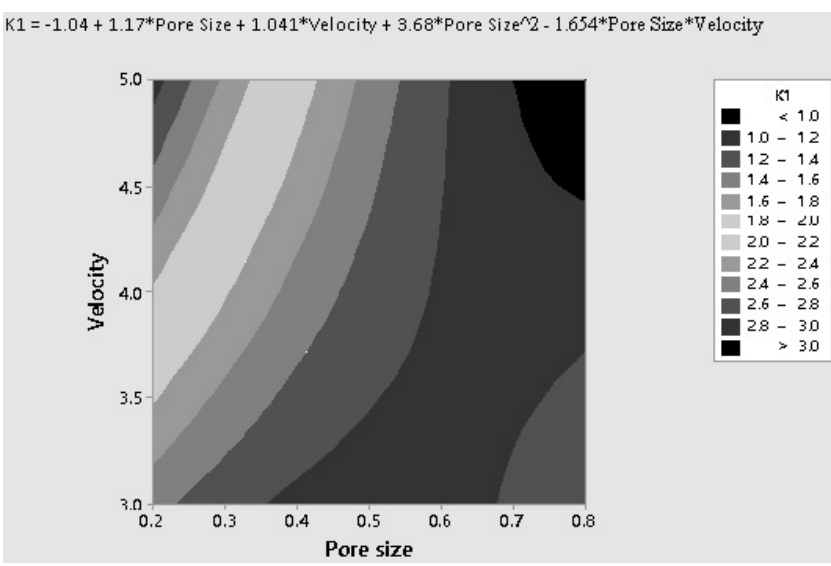

Figure 4: Contour graph $\mathrm{K}_{1}$ for cellulose. Interactions among variables (pressure, velocity, pore size).

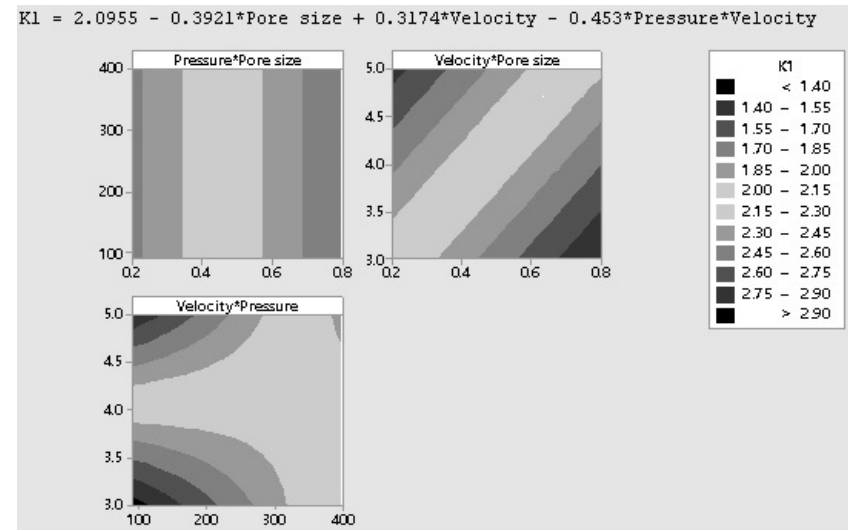

Figure 5: Contour graph $\mathrm{K}_{1}$ for lignin. Interactions among variables (pressure, velocity, pore size)

Therefore, the action of the CFV is not sufficient to remove the macro-solutes accumulated on the fouling layer, while the gel layer is compacted by the action of pressure, and the interactions between macro-solutes/membrane pore size could participate in the consolidation of the cake structure. In this case, the convective flow is larger than the diffusive flow of solutes, and the permeate flow tends to be minimal [39].

For cellulose, $\left(\mathrm{K}_{1}\right)$ is controlled by the pore size and the CFV, despite the small shear stress exerted by the CFV, whereas $\left(\mathrm{K}_{2}\right)$ is controlled by the pore size and TMP (Figure 4).

For lignin, the velocity at which the permeate flows through the fouling layer and the membrane is limited by the pore size and the TMP and is favoured by increasing CFV; therefore, the velocity with which macro-solutes are removed increases with increasing TMP (Table 1).

\section{Conclusion}

Each feed/membrane system illustrates a special case of the phenomenon of fouling, although when cellulose is present in model solutions, the permeate flux is enhanced. The experimentally obtained data showed that pectin is the main macro-compound responsible for the loss of efficiency of tangential microfiltration. Therefore, to reduce potential fouling, enzymatic hydrolysis should be implemented as a 
Citation: Ocampo HLG, Erickson LE, Pasos CAV, Barka FV (2016) Impact of Pectin, Cellulose, and Lignin on Membrane Fouling Indicators during Cross-flow Microfiltration of Model Solutions. J Membra Sci Technol 6: 150. doi:10.4172/2155-9589.1000150

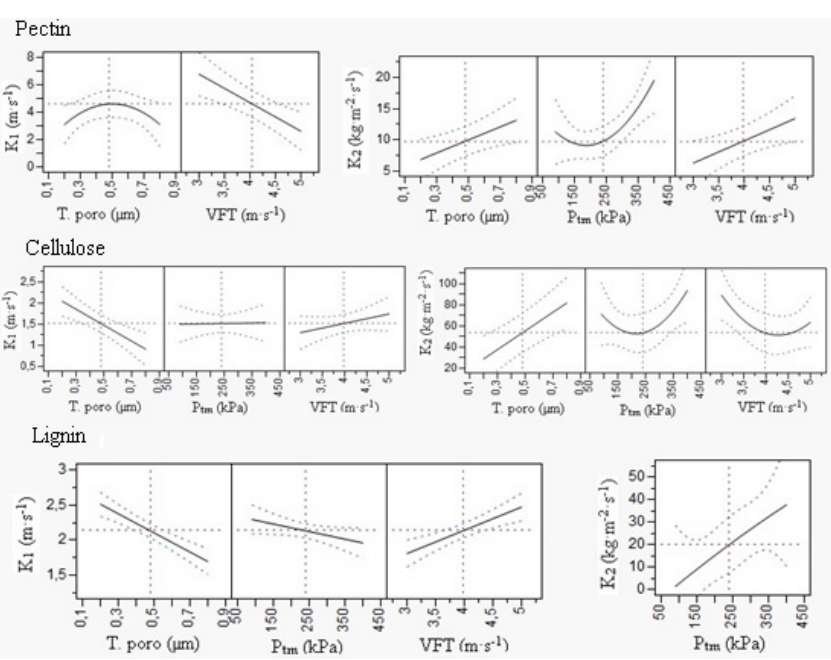

Figure 6: Contour plots for $\mathrm{K}_{1}$ and $\mathrm{K}_{2}$ according to pore size, TMP and CFV.

pretreatment for the CFM process or small amounts of cellulose fibre should be added to reduce the fouling because cellulose fibre does not react with the food.

The optimum operating conditions and pore size to reduce fouling of the membranes depend on the pore size to particle size ratio and the physicochemical interactions between the solute and membrane.

The mathematical model (Equation 9) is useful in the region where the permeate flow is nearly independent of pressure, the pore size and cross-flow velocity but is dependent on the diffusional phenomenon of mass transfer. In this case, the values of the parameters $\mathrm{K}_{1}$ and $\mathrm{K}_{2}$ are dependent on the type of feed used.

\section{Acknowledgments}

The authors would like to thank Colciencias (Colombia) and the Universidad Del Valle for their financial support of this study. The authors would also like to thank the Universidad de Costa Rica for the economic support of the first experimental phase. The Center for Hazardous Substance Research at Kansas State University provided partial support.

\section{References}

1. Girard B, Fukumoto LR (2000) Membrane processing of fruit juices and beverages: A review. Crit Rev Food Sci Nutr 40: 91-157.

2. Sharma SS, Mulvaney SJ, Rizvi SSH (2003) Ingenieria de Alimentos: Operaciones unitarias y practicas de laboratorio. Limusa.

3. Vaillant F, Millan A, Dornier M, Decloux M, Reynes M (2001) Strategy for economical optimisation of the clarification of pulpy fruit juices using crossflow microfiltration. J Food Eng 48: 83-90.

4. Vaillant F, Pérez AM, Acosta O, Dornier M (2008) Turbidity of pulpy fruit juice: A key factor for predicting cross-flow microfiltration performance. J Memb Sci 325: 404-412.

5. Riedl K, Girard B, Lencki RW (1998) Influence of membrane structure on fouling layer morphology during apple juice clarification. J Memb Sci 139: 155-166.

6. Susanto H, Feng Y, Ulbricht M (2009) Fouling behavior of aqueous solutions of polyphenolic compounds during ultrafiltration. J Food Eng 91: 333-340.

7. Srivastava S, Tyagi SK (2013) Effect of enzymatic hydrolusis on the juice yield from apple fruit (Malus Domestica) pulp. International Journal of Biotechnology and Bioengineering Research 4: 299-306.

8. Shamel MM, Sulaiman NM, Sulaiman MZ (1999) Cross flow ultrafiltration studies on solutions of pectin with pulsatile flow in-situ cleaning. Artif Cells Blood Substit Biotechnol 27: 447-453.

9. Rai P, Majumdar GC, Dasgupta S, De S (2010) Flux Enhancement during
Ultrafiltration of Depectinized Mosambi (Citrus Sinensis [L] Osbeck) Juice. J Food Process Eng 33: 554-567.

10. Sarkar B, Pal S, Ghosh TB, De S, DasGupta S (2008) A study of electric field enhanced ultrafiltration of synthetic fruit juice and optical quantification of ge deposition. J Memb Sci 311: 112-120.

11. AOAC (1990) Fruits and fruits products. In: Helrich, editor. Official methods of analysis of the Association of Official Analytical Chemists. Arlington 910-928.

12. Bird RB, Stewart WE, Lightfoot EN (2002) Transport phenomena. Second ed United States of America: Wiley

13. Vela MCV, Blanco SÁ, García JL (2005) Crossflow ultrafiltration of cake forming solutes: a non-steady state model. Desalination 184: 347-356.

14. Tam CM, Tremblay AY (1991) Membrane pore characterization—comparison between single and multicomponent solute probe techniques. J Memb Sci 57 : 271-287.

15. Ramirez LAG, de los Rios CDF, Velez PCA, Gallego OHL (2011) Optimization of the Crossflow Microfiltration of Arazá Juice (Eugenia stipitata) Under Different Operation Modes. Vitae 18:153-61.

16. Dornier M, Petermann R, Decloux M (1995) Influence of start-up procedure on crossflow microfiltration of raw cane sugar. J Food Eng 24: 213-224.

17. Membralox® PE. Membralox $®$ user manual France: Pall Exekia

18. Gan Q, Howell JA, Field RW, England R, Bird MR, et al. (1999) Synergetic cleaning procedure for a ceramic membrane fouled by beer microfiltration. $J$ Memb Sci 155: 277-289.

19. Gan Q, Howell JA, Field RW, England R, Bird MR, O'Shaughnessy CL, et al. (2001) Beer clarification by microfiltration - product quality control and fractionation of particles and macromolecules. J Memb Sci 194: 185-196.

20. Amaro JAA, Ferreira SLC (2004) Application of factorial design and Doehlert matrix in the optimisation of instrumental parameters for direct determination of silicon in naphta using graphite furnace atomic absorption spectrometry. J Anal At Spectrom 19: 246-249.

21. Bezerra Md A, Conceiçâo ALB, Ferreira SLC (2004) Doehlert matrix for optimisation of procedure for determination of nickel in saline oil-refinery effluents by use of flame atomic absorption spectrometry after preconcentration by cloud-point extraction. Analytical and Bioanalytical Chemistry 378: 798-803.

22. Cataldi TRI, Orlando D, Nardiello D, Rubino A, Bianco G, Abate $S$, et al. (2007) A three-factor Doehlert matrix design in optimising the determination of octadecyltrimethylammonium bromide by cation-exchange chromatography with suppressed conductivity detection. Analytica Chimica Acta 597: 129-136.

23. Ferreira SLC, dos Santos WNL, Quintella CM, Neto BCB, Bosque-Sendra JM (2004) Doehlert matrix: a chemometric tool for analytical chemistry-review. Talanta 63: 1061-1067.

24. Box G, Behnken D (1960) Some new three level designs for the study of quantitative variables.

25. Capannelli G, Bottino A, Munari S, Lister DG, Maschio G (1994) The use of membrane processes in the clarification of orange and lemon juices. J Food Eng 21: 473-483.

26. Rezaei H, Ashtiani FZ, Fouladitajar A (2014) Fouling behavior and performance of microfiltration membranes for whey treatment in steady and unsteady-state conditions. Brazilian Journal of Chemical Engineering 31: 503-518.

27. Sulaiman MZ, Sulaiman NM, Shamel M (2001) Ultrafiltration studies on solutions of pectin, glucose and their mixtures in a pilot scale crossflow membrane unit. Chemical Engineering Journal 84: 557-563

28. SIGMA-ALDRICH. Lignin, alkali.

29. Lu H, Gui Y, Zheng L, Liu X (2013) Morphological, crystalline, thermal and physicochemical properties of cellulose nanocrystals obtained from sweet potato residue. Food Research International 50: 121-128

30. Zhao J, He X, Wang Y, Zhang W, Zhang X, Zhang X, et al. (2014) Reinforcement of all-cellulose nanocomposite films using native cellulose nanofibrils. Carbohydrate Polymers 104: 143-150.

31. Cardoso de Oliveira R, Docê RC, de Barros STD (2012) Clarification of passion fruit juice by microfiltration: Analyses of operating parameters, study of membrane fouling and juice quality. J Food Eng 111: 432-439. 
Citation: Ocampo HLG, Erickson LE, Pasos CAV, Barka FV (2016) Impact of Pectin, Cellulose, and Lignin on Membrane Fouling Indicators during Cross-flow Microfiltration of Model Solutions. J Membra Sci Technol 6: 150. doi:10.4172/2155-9589.1000150

32. Koltuniewicz AB, Field RW, Arnot TC (1995) Cross-flow and dead-end microfiltration of oily-water emulsion. Part I: Experimental study and analysis of flux decline. J Memb Sci 102: 193-207.

33. Koltuniewicz A (1992) Predicting permeate flux in ultrafiltration on the basis of surface renewal concept. J Memb Sci 68: 107-118.

34. Koltuniewicz A, Noworyta A (1994) Dynamic Properties of Ultrafiltration Systems in Light of the Surface Renewal Theory. Industrial \& Engineering Chemistry Research 33: 1771-1779.

35. Constenla DT, Lozano JE (1996) Predicting Stationary Permeate Flux in the Ultrafiltration of Apple Juice. LWT - Food Science and Technology 29: 587-592.

36. Arnot TC, Field RW, Koltuniewicz AB (2000) Cross-flow and dead-end microfiltration of oily-water emulsions: Part II. Mechanisms and modelling of flux decline. J Memb Sci 169: 1-15.

37. Sarkar D, Datta D, Sen D, Bhattacharjee C (2011) Simulation of continuous stirred rotating disk-membrane module: An approach based on surface renewal theory. Chemical Engineering Science 66: 2554-2567.

38. Hasan A, Peluso CR, Hull TS, Fieschko J, Chatterjee SG (2013) A surfacerenewal model of cross-flow microfiltration. Brazilian Journal of Chemical Engineering 30: 167-86.

39. Pagliero C, Ochoa NA, Marchese J (2011) Orange Juice Clarification by Microfiltration: Effect of Operational Variables on Membrane Fouling. Latin American applied research 41: 279-284.

40. Jiraratananon $R$, Chanachai $A$ (1996) A study of fouling in the ultrafiltration of passion fruit juice. J Memb Sci 111: 39-48
41. Qu Y, Luo H, Li H, Xu J (2015) Comparison on structural modification of industrial lignin by wet ball milling and ionic liquid pretreatment. Biotechnology Reports 6: 1-7.

42. Hu L, Pan H, Zhou Y, Zhang M (2011) Methods to improve lignin's reactivity as a phenol substitute as replacement for other phenolic compounds: A brief review. BioResources 6: 3515-3525.

43. Li D, Briens C, Berruti F (2015) Improved lignin pyrolysis for phenolics production in a bubbling bed reactor - Effect of bed materials. Bioresource Technology 189: 7-14

44. Banerjee S, De S (2012) An Analytical solution of Sherwood number in a stirred continuous cell during steady state ultrafiltration. J Memb Sci. 389: 188-196.

45. Verma SP, Sarkar B (2015) Analysis of flux decline during ultrafiltration of apple juice in a batch cell. Food and Bioproducts Processing 94: 147-157.

46. Sourav M, Chhaya R, Sirshendu D (2013) Identification of fouling mechanism during ultrafiltration of stevia extract. Food and Bioprocess Technology 6: 931-940.

47. Rezzadori K, Serpa L, Penha FM, Petrus RR, Petrus JCC (2014) Crossflow microfiltration of sugarcane juice: effects of processing conditions and juice quality. Food Science and Technology (Campinas) 34: 210-217.

48. Machado RMD, Haneda RN, Trevisan BP, Fontes SR (2012) Effect of enzymatic treatment on the cross-flow microfiltration of açai pulp: Analysis of the fouling and recovery of phytochemicals. J Food Eng 113: 442-452. 